\title{
SIMBOL RELIGIUS PADA RUMAH GADANG ABAI SANGIR, SOLOK SELATAN
}

\section{Dedi Gusman}

\author{
Abstract
}

This research describes religious symbols at rumah gadang Abai Sangir Solok Selatan. The symbols lay on walls, stairs, doors, and windows. Using the descriptive qualitative method and Paul Ricoer theory, the research shows that the society put on their belief on those symbols. How they live as person and society described on the symbols.

Key word: simbol, rumah gadang, Abai Sangir, hermeneutika

\section{Pengantar}

Secara substansial simbol atau lambang religius bersifat keagamaan yang berkenaan dengan kepercayaan dogma dan agama (Novia, t.t: 482). Jadi membaca simbol religius adalah melihat dan menghayati suatu simbol baik berupa huruf atau angka dengan pena dan sebagainya yang terdapat di atas kertas atau yang lainnya bersifat keagamaan yang berkenaan dengan kepercayaan agama. Di Nagari Abai Sangir simbol-simbol religius berada di rumah gadang dan sangat disakralkan oleh masyarakat Abai Sangir sebagai kosmologi alam, manusia dan Tuhan Yang Maha Tinggi dan Maha Agung. Unsur simbol religius yang akan dibahas dalam penelitian ini nanti akan membahas; 1) sekelompok masyarakat; 2) para pembuat atau yang menciptakan simbol religius yang terikat dalam suatu; 3) sistem atau norma yang dipahami sebagai pengantar peristiwa sakral.

Senada dengan penjelasan di atas, Khanizar (2009:1) menyatakan bahwa budaya adalah "sesuatu" yang hidup, berkembang dan bergerak menuju titik ruang, waktu dan tempat dari kebudayaan yang bersifat dinamis dan dialektis. Religiusitas sangat terikat dengan berbagai bidang 
sehingga antarunsur tersebut saling berkaitan satu sama lain. Religius bukanlah hasil dari sebuah tumpukan fenomena-fenomena yang terjadi, tetapi tersusun dengan rapi, teratur dan mengandung nilai atau makna dan dihasilkan oleh sekelompok sosial masyarakat tertentu.

Fenomena membaca lebih sering diungkapan dengan pemahaman yang cukup kompleks. Membaca berkaitan langsung dengan praktek sosial dan interaksi manusia dalam kehidupan sehari-hari. Membaca merupakan kawasan dari bahasa yang dapat dipahami. Membaca tulisan religius merupakan cara untuk memahami sebuah ilmu pengetahuan atau makna yang terdapat pada tulisan tersebut. Melalui membaca tulisan religius tersebut akan di dapatkan cara pemahaman atau pemaknaan terhadap tulisan religius dan implikasi-implikasi yang di timbulkan oleh suatu objek.. Membaca tulisan religius merupakan sebuah rangkaian teks-teks yang mempunyai tindakan-tindakan yang penuh makna yang terdapat didalamnya. Tentu saja, membaca tersebut akan terbangun oleh kekuatan dan intensitas teks supaya dapat dibaca dan dipahami oleh orang lain.

Penelitian ini menggunakan pemikiran Paul Ricoeur yang memberikan tekanan terhadap teksnya sendiri dalam memahami (verstehen) makna sebuah teks dan bacaan. Jika objektivitas penafsiran ingin capai paling tidak secara relatif kita harus bertumpu pada teks agar dia berbicara sendiri (Cristomy dan Yowono, 2004:62).

Adapun simbol religius yang dibahas adalah simbol-simbol sakral yang terdapat di rumah gadang di Nagari Abai Sangir Kecamatan Abai Sangir Jujuang Kabupaten Solok Selatan. Di daerah ini terdapat delapan buah rumah gadang dan tiap rumah gadang mempunyai datuk dan tuo sukunya. Masing-masing tuo suku bertanggung jawab atas keberadaan suku dan rumah gadangnya sebagai ukuran masyarakat adat di Abai Sangir. Rumah gadang di Nagari Abai selain dikenal sebagai sebutan rumah gadang tetapi juga di sebut sebagai rumah bayi karena di atas rumah gadang terjadinya alek baik dan alek buruk.

Sampai sekarang di Nagari Abai masih terdapat rumah gadang yang berfungsi dan terpelihara, salah satunya rumah gadang tersebut adalah rumah gadang "daulat" yang dipertuan Rajo Tigo Selo, empat belas suku penghulunya di dalam nagari Abai. Fungsi dan guna rumah gadang tersebut sebagai tempat bermusyawarah, tempat baiyo batido dan kalau alek baik dan alek buruk, seperti alek syukuran dan alek perkawinan. Alek buruknya seperti alek kematian, walaupun malam itu lahirnya seorang bayi dan paginya 
meninggal dunia harus dibawa ke rumah gadang. Seandainya tidak dibawa ke rumah gadang, maka ninik mamak tidak akan menghadirinya. Maka dari itu rumah gadang di nagari Abai masih berfungsi dan utuh sampai sekarang. Simbol-simbol religius tersebut terdapat pada rumah-rumah gadang.

\section{Landasan Teori}

Teori yang digunakan dalam penelitian ini adalah hermeneutika Paul Ricour. Secara etimologis, hermeneutika berasal dari bahasa Yunani, yang berarti"menjelaskan" (erkalaren, explain). Kata tersebut kemudian diserap ke dalam bahasa Jerman hermeneutika dan bahasa Inggris hermeneutics. Sebagai sebuah istilah, kata tersebut didefinisikan sebagai "ajaran tentang proses pemahaman interpretatif, juga tentang pemberian arti atau penafsiran". Meskipun para ahli memberikan definisi yang agak berbeda, tetapi ada kesepakatan bahwa hermeneutika digunakan untuk memahahi ungkapanungkapan yang karena faktor yang sulit untuk dipahami.

Ricoeur merancang hermeneutika sebagai teori umum interpretasi dengan menggarap epistemologi interpretasi, tetapi secara lebih spesifik diarahakan kepada interpretasi teks. Pada hermeneutika tanda-tanda, dan lebih fundamental lagi pada keberadaan kenyataan "aku berada" (je suis), pada hermeneutika keberadaan subjek (Poespoprodjo, 2004: 107). Ricouer mengatakan tugas utama hermeneutik ialah di suatu pihak mencari dinamika internal yang mengatur struktur kerja suatu teks, di lain pihak mencari daya yang dimiliki kerja teks itu untuk memproyeksikan diri keluar dan memungkinkan "hal" nya teks itu muncul ke permukaan (Sumaryono, 1999: 107). Hermeneutik juga mempunyai tugas untuk mengenali ihwalnya teks atau dunia teks atau dunia kenyataan yang dibahasakan oleh teks dan bukan jiwa pencipta. Masalah hakiki bukan mendapatkan kembali di balik teks maksud yang hilang, tetapi membentangkan di hadapan teks, dunia yang dibukakan dan dunia yang diperlihatkan oleh teks (Ricouer dalam Poepoprodjo,2004: 113). Ada tiga langkah pemahaman hermeneutik menurut Ricouer. Langkah pertama adalah langkah simbolik, atau pemahaman dari simbol ke simbol. Langkah kedua adalah pemberian makna atas simbol serta penggalian yang cermat atas makna. Langkah ketiga adalah langkah yang benar-benar filosofis, yaitu berfikir dengan mengunakan simbol sebagai titik tolaknya. 


\section{Metode dan Teknik Penelitian}

Metodeyangdigunakandalampenelitianiniadalahkualitatifdeskriptif. Adapun teknik yang dilakukan adalah sebagai berikut.

1 Pengumpulan Data

Data dikumpulkan dengan teknik pengumpulan data seperti dalam penelitian hermeneutik, sedangkan cara kerja yang terkait dengan apa yang harus di perbuat, sumber datanya adalah simbol-simbol religius yang terdapat pada rumah gadang Abai Sangir.

\section{Analisis Data}

Data dianalisis mengunakan teori hermeneutika. Analisis ini dilakukan untuk mencari makna berdasarkan konteks masyarakat. Langkahnya adalah menggabungkan data yang pertama dengan nilai-nilai kebudayaan masyarakat.

3 Penyajian Analisis Data

Sajian data analisis bersifat deskriktif. Artinya hasil analisis diuraikan menggunakan kata-kata berdasarkan analisis yang telah dilakukan.

\section{Simbol pada Rumah Gadang Abai Sangir}

Masyarakat Nagari Abai Sangir Solok Selatan hanya menyebut simbolsimbol objek penelitian ini sebagai rajah. Kejelasan tentang simbol-simbol yang ada pada rumah gadang tidak ada yang mau menerangkan dengan jelas. Tidak semua data yang diperoleh dapat dikelompokkan ke dalam bentuk simbol religius. Pengelompokkan dilakukan berdasarkan letak gambar dan simbol tersebut, yaitu pada daun pintu, pada kusen pintu, pada tiang rumah, dan pada tangga.

Langkah pemahaman yang dilakukan dalam penelitian ini adalah tiga langkah pemahaman hermeneutika menurut Ricouer. Langkah pertama adalah langkah simbolik, atau pemahaman dari simbol ke simbol. Langkah kedua adalah pemberian makna atas simbol serta penggalian yang cermat atas makna. Langkah ketiga adalah langkah yang benar-benar filosofis, yaitu berfikir dengan mengunakan simbol sebagai titik tolaknya. 
Simbol Religius ...

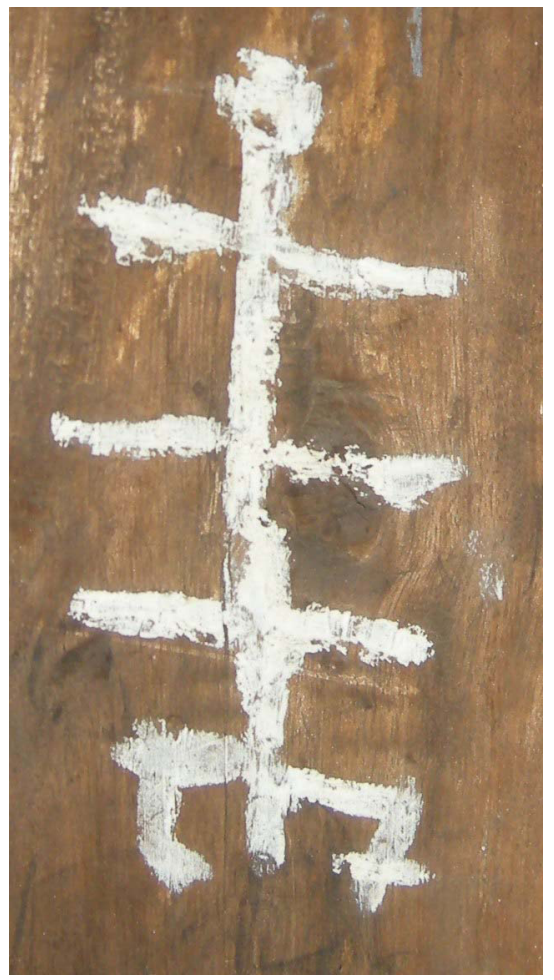

Gambar 1

Gambar simbol di atas menyerupai tulang ikan, Hal ini bisa diinterpretasikan kedekatan masyarakat dengan hasil alam (ikan) karena Nagari Abai Sangir di alui oleh aliran sungai Batanghari. Para penghuni rumah gadang di Nagari AbaiSangir harus rajin dalam melakukan pekerjaan tidak pandang apapun perkerjaannya yang penting pekerjaannya halal. Simbol tulang ikan pada simbol pertama sangat dihargai dan dipahami sebagai kesejahteraan keluarga atau kaum tempat terdapat simbol. 


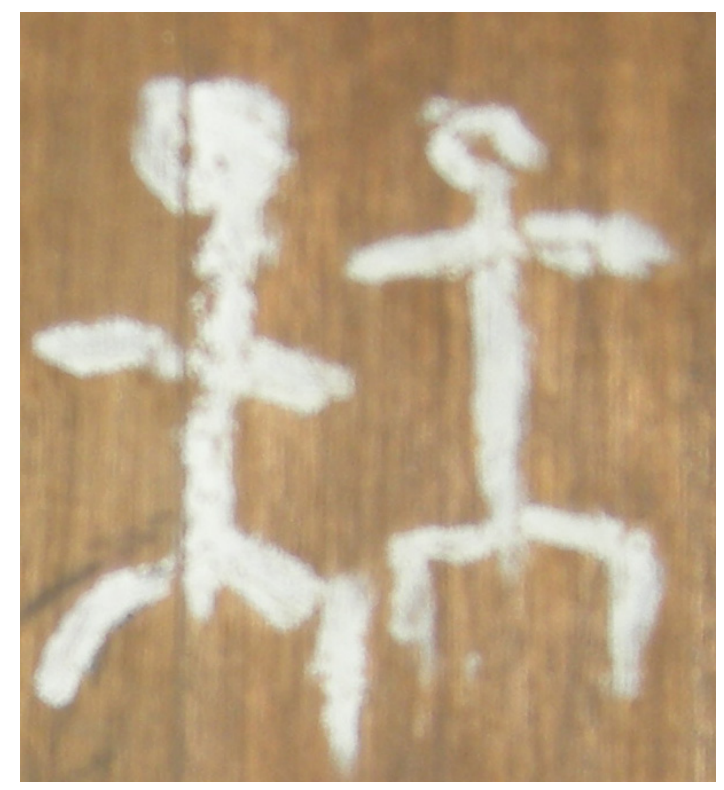

Gambar 2

Simbol kedua melambangkan keadaan suatu kondisi kaum yang menghuni rumah gadang. Simbol kedua dapat dianalogikan ke dalam kehidupan masyarakat setempat yaitu bahwa kaum atau orang yang berada di atas rumah hidup rukun sehingga jarang terjadi kesalampahaman atau pertengkaran.

Apabila ingin hidup sejahtera dan damai di dalam kehidupan masyarakat maka terlebih dahulu harus bisa hidup berdampingan dengan anggota keluarga yang tinggal di rumah gadang maupun antarkaum satu pesukuan atau satu atap rumah gadang yang ditempati. Penghuni rumah atau kaum yang memiliki rumah gadang sangat menjaga hubungan baik. 


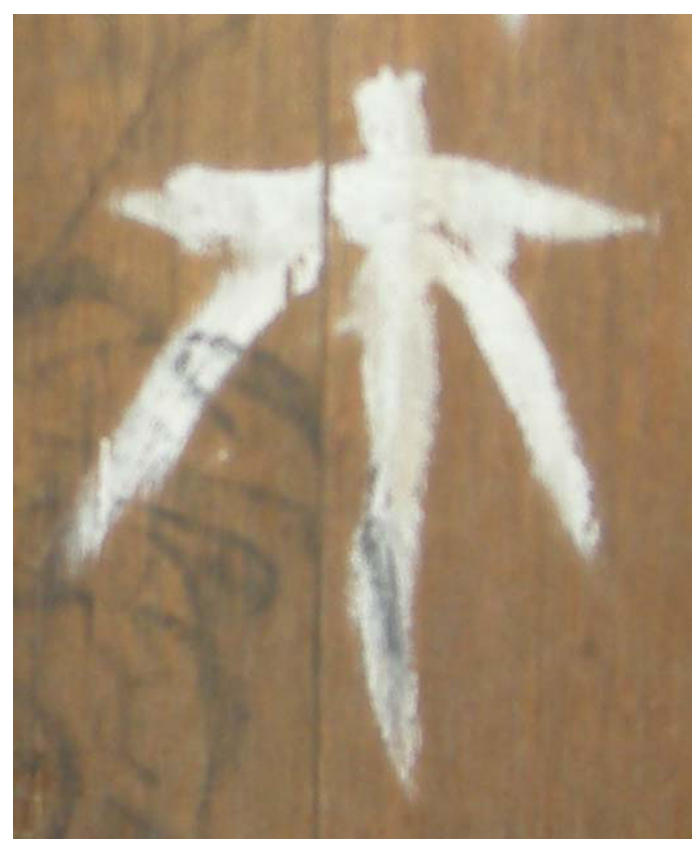

Gambar 3

Simbol ketiga melambangkan tanggung jawab seorang penghulu pucuak rumah gadang. Tanggung jawab penghulu pucuak kaum yang besar adalah membina, membimbing, dan menjaga dengan baik adat kaum mereka agar tidak semena-mena dilanggar oleh anggota kaum.

Simbol ketiga menyerupai lambang seseorang yang berdiri tegak dan ada yang bergantung (garis yang berdiri tegak di simbolkan sebagai simbol penghulu dan 2 buah garis miring di simbolkan sebagai kaum, kemenakan yang bergantung kepada mamak). Simbol ini mengandung makna bahwasanya mamak di atas rumah gadang mempunyai tanggung jawab yang besar terhadap para anggota kaum mereka. Apabila terjadi perselisihan antarkaum mamak yang menyelesaikan bukan orang lain yang di luar kaum mereka. Sebuah acara yang akan dilakukan harus memberi tahu mamak kepala kaum. 


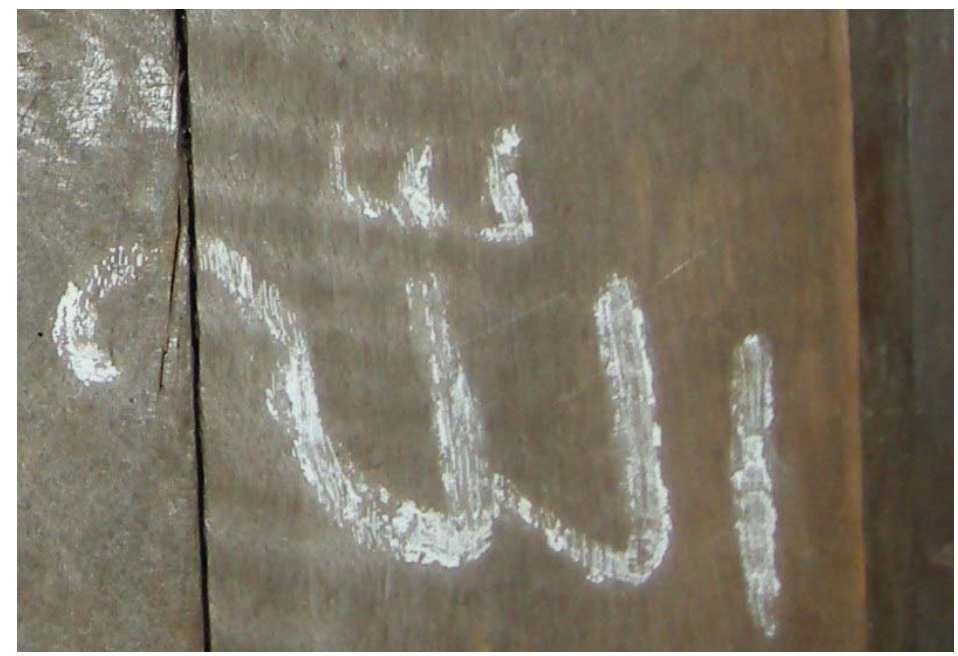

Gambar 4

Simbol keempat melambangkan kepercayaan terhadap Allah SWT (sang pencipta), Masyarakat yang memiliki simbol sangat mempercayai adanya tuhan yang menciptakan langit dan bumi ini sehingga masyarakat meyakini apa yang terjadi adalah kehendak allahSWT. Apabila dianalogikan simbol tersebut melambangkan bahwasanya orang yang tinggal di atas rumah gadang mempercayai dan meyakini bahwa tuhan itu ada dan mereka merupakan pemeluk agama Islam seperti masyarakat yang lain yang menganut agama.

Melalui kajian simbol-simbol yang ada dalam simbol dapat dipahami bagaimana cara masyarakat Abai Sangir Batang Hari mempertahankan struktur sosial dan agamanya, salah satunya dengan melakukan proses penulisan pada bagian-bagian tertentu rumah gadang pada proses inisiasi dimana mereka diberi pemahaman mengenai peranan mereka dalam struktur sosial, agama yang ada.

Simbol bisa menjadi kendaraan yang mengantarkan kita kepada pemahaman bagaimana manusia mengenal dan menerima hakekat dari kehidupan sosial, agama di masyarakatnya. Apabila orang datang berkunjung ke rumah gadang tersebut dan ditawari makan, orang yang berkunjung tidak akan ragu untuk memakan apa yang telah disediakan oleh tuan rumah. 


\section{Penutup}

Pola hidup masyarakat adat Abai Sangir Kabupaten Solok Selatan dalam bentuk simbol religius di rumah gadang adalah bentuk pengejawantahan kepercayaan masyarakatnya. Di samping itu, masyarakat Abai Sangir mempunyai kepercayaan sekaligus merupakan gagasan atau ide dan pola kehidupan masyarakat yang menciptakanya sehingga tradisi tentang simbol dan bacaan budaya suatu daerah khususnya di Abai Sangir akan terangkat ke permukaan sebagai puncak kearifan lokal masyarakat Solok Selatan.

\section{Daftar Pustaka}

Atho \& Fahrudin. 2002. Hermeneutika Transcendental Dari Konfigurasi Filosofis Menuju Praktis Islam Studies. Yogyakarta : CIRCisoD.

Bungin (Ed), Burhan. 2004. Metodologi Penelitian Kualitatif. Jakarta : PT Raja Garfindo Persada.

Crhistomy, Tommy. 2004 Indonesia Tanda yang Retak. Jakarta: Wedatama Widyasastra.

Endraswara, Suwardi. 2009. Metode, Teori, Teknik Metode Penelitian Kebudayaan: Ideology, Epistemology,Dan Aplikasi, Yogyakarta : Pusataka Widayatama.

2009. Metodologi Penelitian Folklor. Yogyakarta : Media Pressindo.

Eliade, mircea. 2002. Sakral dan Propan Menyingkap Hakikat Agama. Yogyakarya : Fajar Pustaka Baru.

Herwandi, (Ed). 2004. Mambangkik Batang Tarandam, Kumpulan Makalah Seminar Internasional Kebudayaan Minangkabau. Padang: Pemda Sumbar dan Panitia Seminar Kebudayaan Minangkabau.

Johanes, Rio. 2008. Tinjauan Hermeneutika Paul Ricoeur Terhadap Silek Perguruan Seni Tradisi Singo Barantai (PSSB): Studi Budaya. Universitas Andalas. Padang.

Khanizar. 2009.Dari Bacaan Tabuik: Hingga Membingkai Kesadaran Etnisitas Di Pantai Barat Sumatera Barat. Padang.

Koenjaraningrat. 1996. Pengantar Antropologi I. Jakarta: PT Rineka Jaya.

Navis. A.A. 1984. Alam Takambang Jadi Guru. Jakarta : Pustaka Grafitipers.

Novia. Windy, s.pd, Kamus Lengkap Bahasa Indonesia. Kashiko Press.

Poespoprodjo, W. 2004. Hermeneutika. Bandung : Pustaka Setia.

Sawirman, 2005. Simbol Lingual Teks Politik Tan Malaka Eksplorasi, Signifikasi

Dan Trans Figurasi Interteks: Pasca Sarjana. Unversitas Udayana. Denpasar.

Sumaryono, E. 1999. Hermeneutika Sebuah Metode Filsafat. Yogyakarta : Kanisius. 
